\title{
Response patterning as a function of the percentage of reinforcement associated with serial trial position
}

\author{
STEVEN J. HAGGBLOOM and TERRY A. HOLLINGSHEAD \\ Arkansas State University, State University, Arkansas 72467
}

\begin{abstract}
In Experiment 1, three groups of 10 rats each received 4 trials/day on schedules of partial reinforcement under which the percentage of reinforcement associated with each successive serial trial position within days increased across trials (Group I), decreased across trials (Group D), or varied according to a U-shaped function (Group U). Three of the four daily trials occurred in one (e.g., black) runway, and one trial each day, called a probe trial, occurred in another (e.g., white) runway. Within blocks of 4 days, the probe trial occurred in each of the four possible serial positions. As the probe trial rotated through Positions 14, speeds on that trial increased in Group I, decreased in Group D, and varied according to a U-shaped function in Group U. Experiment 2 employed two groups of 10 rats each, Groups I and $\mathrm{D}$, and demonstrated that the patterning behavior obtained in those groups in Experiment 1 was a reliable phenomenon. The results are discussed in relation to response patterning as a function of variations in reward magnitude across trials and a putative ability of the rat to keep track of serial trial position by counting.
\end{abstract}

Rats can learn to respond appropriately to a variety of complex patterns of reinforcement. For example, given an alternating pattern of rewarded (R) and nonrewarded (N) trials (e.g., Bloom \& Capaldi, 1961) or an alternating pattern of large (L) and small (S) R trials (Bloom, Williams, \& Metze, 1973), rats learn to run faster on R (or L) trials than on N (or S) trials. Given a series of $\mathrm{L}$ trials and a series of either $\mathrm{N}$ (Haggbloom \& Tillman, 1980) or S (Haggbloom, 1979) trials on alternate days, rats learn to run faster on the more favorably reinforced days than on the less favorably reinforced days. Rats can also learn to discriminate the occasions for reinforcement from those for nonreinforcement when all daily reinforced trials precede daily nonreinforced trials and vice versa (Capaldi, 1979; Haggbloom, 1981). Finally, rats can learn to respond appropriately to a variety of both monotonic (e.g., Capaldi, Blitzer, \& Molina, 1979; Hulse, 1978) and nonmonotonic (Capaldi \& Molina, 1979) changes in reinforcement magnitude across daily trials.

Consider nonreward to be the zero value on a rewardmagnitude scale. Then the experiments cited above can all be said to provide evidence of a marked ability in

Experiment 1 was presented to the meeting of the Midwestern Psychological Association, May 1979, St. Louis. These experiments were supported by grants from Arkansas State University to the senior author. The authors wish to thank John K. Beadles for the use of laboratory space in the Department of Biology. Requests for reprints should be addressed to Steven J. Haggbloom, Department of Psychology, Arkansas State University, P.O. Box 2127, State University, Arkansas 72467. the rat to learn to respond appropriately to regular variations in reward magnitude across trials. Both experiments reported here were concerned with whether rats could learn to respond appropriately to variations in percentage of reinforcement across trials. That they might be able to do so was initially suggested by the results of Experiment 1, which was conducted for a different purpose, and was supported by the results of Experiment 2.

\section{EXPERIMENT 1}

Experiment 1 was conducted as part of a series of experiments (e.g., Haggbloom, 1980) that investigated the effects of sequence of partial reward in the positive $(\mathrm{S}+)$ stimulus on extinction of responding to the negative (S-) stimulus in differential conditioning. The experiment employed the same reinforcement schedules used by McHose and Blackwell (1975, Experiment 2). Three groups differed with respect to the daily schedule of $\mathrm{R}$ and $\mathrm{N}$ trials received in S+: NRR, RNR, or RRN. A single, nonrewarded, $\mathrm{S}-$ trial was presented each day. This trial, referred to here as a probe trial, occurred in each of the four possible trial positions within each successive block of 4 days.

There were no overall differences between groups in amount of responding to $S$ - as a function of $S+$ reward schedule. However, each of the three groups showed an idiosyncratic response pattern over successive probe trials. An examination of the reinforcement schedules revealed that the percentage of reinforcement associated with each of the four daily trial positions increased 
across trials in the NRR schedule condition (identified here as Group I), decreased across trials in the RRN schedule condition (identified here as Group D), and varied according to a U-shaped function in the RNR schedule condition (identified here as Group $U$ ). As the probe trial rotated through the four possible trial positions over days, each group's speed of running on that trial was directly related to the percentage of reinforcement associated with that serial trial position. Thus, as the probe trial rotated through Positions 1-4, speeds on that trial increased in Group I, decreased in Group D, and varied according to a U-shaped function in Group $U$. It is this patterning behavior on probe trials that is of interest here.

\section{Method}

Subjects. In both of the experiments reported here, 10 male rats, bred in the laboratory from Holtzman stock and approximately 90 days old at the beginning of the experiment, were assigned to each group.

Apparatus. The same apparatus was used in both experiments. It consisted of two parallel straight alleys, $105 \mathrm{~cm}$ long $x 9 \mathrm{~cm}$ high and wide. The walls and floor of one alley were painted white, and the walls and floor of the other alley were painted black. The last $25 \mathrm{~cm}$ of each alley constituted a goalbox separated from the rest of the alley by a manually operated guillotine door. The doors and goalboxes were painted the same color as the alley in which they were located. Each goalbox contained an unpainted wooden goal cup. A gray startbox, $9 \mathrm{~cm}$ high and wide $\times 25 \mathrm{~cm}$ long, could be aligned to permit entry into one alley or the other. The startbox had a gray, manually operated guillotine door. Start times were recorded from the opening of the startbox door, which triggered a .01-sec clock, to a point $32 \mathrm{~cm}$ into the alley. Run and goal times were recorded over the next 40 and $30 \mathrm{~cm}$, respectively, of the alley. The offset of the first clock and the operation of the run and goal clocks were controlled by photoelectric circuitry.

Procedure. The following procedures were the same in both experiments. Two weeks prior to the 1st day of experimental training, which began on Day 15 , all food was removed from each rat's cage and a daily ration of $12 \mathrm{~g}$ of lab chow was begun. The rats had free access to water at all times. On Days 12 14 , the rats were handled in squads of two or three for approximately $3 \mathrm{~min} / \mathrm{squad}$. After being handled on those days, the rats were fed eight 45-mg Noyes pellets in their home cages.

During training, the rats were removed from the goalbox on $\mathrm{R}$ trials after the times were recorded (after approximately $10 \mathrm{sec}$ ) unless the reward had not yet been consumed. All reinforcements consisted of eight 45-mg Noyes pellets. On $\mathrm{N}$ trials, the rats were confined to the unbaited goalbox for $20 \mathrm{sec}$.

A trial was begun by placing a rat in the startbox and opening the startbox door after approximately $3 \mathrm{sec}$, regardless of the rat's orientation. The rats were run in squads containing one rat from each group. The order in which trials were administered within a squad varied randomly from day to day, but the order of successive squads was held constant across days. A maximum time of $30 \mathrm{sec}$ was allowed in each section of the alley. If $30 \mathrm{sec}$ was exceeded in any alley section, the additional time was added to the time score of the next section forward. If the rat did not enter the goalbox within $90 \mathrm{sec}$, it was placed in the goalbox.

All S+ trials occurred in the black runway and the probe trial occurred in the white runway for one-half of the subjects in each group. These conditions were reversed for the remaining subjects in each group.

Design. Three groups differed with regard to the sequence of $\mathrm{R}$ and $\mathrm{N}$ trials received in $\mathrm{S}+$ : either NRR (identified here as Group I), RRN (identified here as Group D), or RNR (identified here as Group $U$ ). Each group received a single daily non- rewarded probe $\left(\mathrm{S}^{-}\right)$trial each day. The probe trial occurred in each of Trial Positions 1.4 within successive blocks of 4 days, according to the following recursive sequence: Trials $3,2,1$, and 4.

The percentage of reinforcement associated with each of the four within-day trial positions was $77.8 \%, 72.2 \%, 50.0 \%$, and $0 \%$, respectively, in Group D, $77.8 \%, 27.8 \%, 27.8 \%$, and $77.8 \%$, respectively, in Group $\mathrm{U}$, and $0 \%, 50.0 \%, 72.2 \%$, and $77.8 \%$, respectively, in Group I.

\section{Results and Discussion}

All time scores were converted to speeds in centimeters per second. Only speeds over the total alley are reported here. Figure 1 shows running speeds for each group on the single daily probe trial on each of the last 4 days of training as a function of probe trial position. As can be seen, running speeds increased over trial positions along with the increase in reinforcement percentage in Group I, decreased over trial positions along with the decrease in reinforcement percentage in Group D, and varied according to a U-shaped pattern in Group $U$, matching the U-shaped pattern of reinforcement percentage across trial positions in that group.

It is important to note that the pattern of responding observed on probe trials and shown in Figure 1 occurred only on probe trials and varied as a function of the serial position of the trial. No patterning behavior occurred in St.

An analysis of variance (ANOV.A) with groups (three) and brightness (two) as between-subjects variables and trial position (four) as a within-subjects variable was applied to speeds over the four probe trials shown in Figure 1. The ANOVA showed that there was a reliable Groups by Trial Position interaction $[F(6,72)$ $=4.37, \mathrm{p}<.01]$. Subsequent Newman-Keuls tests showed that Group D ran faster on Trial 1 than on Trial $4(\mathrm{p}<.05)$, Group $U$ ran faster on Trials 1 and 4 than on Trials 2 and 3 (ps $<.05$ ), and Group I ran

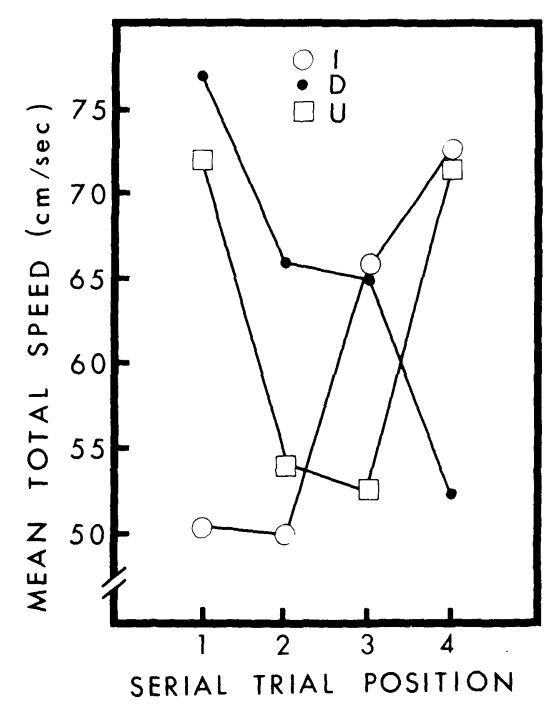

Figure 1. Mean speed of each of the three groups in Experiment 1 on the last four probe trials as a function of the serial position of the probe trial. 
faster on Trial 4 than on Trial $1(p<.05)$. Thus, in the present experiment, speed of running on probe trials was a function of serial trial position within a day's trials and was directly related to the percentage of reinforcement associated with that trial position.

The three groups in Experiment 1 differed with respect to the first-order probabilities of $\mathrm{R}$ or $\mathrm{N}$ following either $\mathbf{R}$ or $\mathbf{N}$. A few examples, however, will show that these differences cannot account for the patterning behavior obtained on probe trials. In Group $\mathrm{U}$, the probability of $\mathrm{R}$ following an $\mathrm{N}$ trial $(\mathrm{R} / \mathrm{N})$ was .31 ; the probability of $\mathrm{N}$ following an $\mathrm{N}$ trial $(\mathrm{N} / \mathrm{N})$ was .14. Nevertheless, running speeds in Group U were quite slow when the probe trial occurred in Serial Position 3, although that trial always followed an $\mathrm{N}$ trial. Group $\mathrm{U}$ ran fast on Trial 4 whether that trial occurred in $\mathrm{S}+$ or was a probe trial. When Trial 4 occurred in $\mathrm{S}+$, it always followed an $\mathrm{N}$ trial (probability of $\mathrm{R} / \mathrm{N}=.31$ ); when it was a probe trial, it followed an $R$ trial in $S+$ and the probability of $R$ following and $R$ trial (R/R) in Group U was zero. Group D ran relatively fast when the probe trial occurred in Position 2, a trial following an $\mathrm{R}$ trial, although the probability of $N / R=.33$, a value greater than the probability of $R / R=.18$. Group $D$ ran slowest when the probe trial occurred in Serial Position 4, a trial following an $\mathrm{N}$ trial, although the probability of $\mathrm{N} / \mathrm{N}=$ the probability of $\mathrm{R} / \mathrm{N}=.125$.

The explanation of the patterning behavior obtained on probe trials that is favored here is that habit strength (H) varied over trial positions within each group as a function of the percentage of reinforcement associated with a given trial position. Differences in $\mathrm{H}$ associated with each trial position were not reflected in behavioral differences over trials in S+ because, for each trial position, $\mathrm{H}$ equaled or exceeded the value necessary to produce asymptotic running speeds. On probe trials, however, there was only a generalized tendency to respond. Consequently, running speeds were below asymptote and differences in $\mathrm{H}$ associated with serial trial position within each group were reflected in a pattern of responding that matched the pattern of reinforcement percentage across trial positions. The probe trials detected differences in $\mathrm{H}$ associated with serial trial position that might otherwise not have been detected.

\section{EXPERIMENT 2}

As indicated, Experiment 1 was not designed for the purpose of investigating response pattern as a function of reinforcement percentage associated with a particular serial trial position. The purpose of Experiment 2 was to check on the reliability of the patterning behavior obtained in Experiment 1 in a design specifically intended to produce it. There were two groups in Experiment 2, Group I and Group D. Both groups received 4 trials/day. Over the course of the experiment, the percentage of reinforcement associated with Trial Positions $1-4$ was $0 \%, 25 \%, 50 \%$, and $75 \%$, respectively, in Group I and 75\%, 50\%, 25\%, and 0\%, respectively, in Group D. As in Experiment 1, three of the four daily trials occurred in one runway brightness and a single, always nonrewarded, probe trial occurred each day in the opposite brightness runway. Within blocks of 4 days, the probe trial rotated through Trial Positions 1-4. It is the pattern of responding across days on this single daily probe trial that is of primary interest in Experiment 2.

\section{Method}

There were two groups in Experiment 2, Groups I and D. Both groups received 4 trials/day, 3 in one brightness runway and the 4 th, the probe trial, in the opposite brightness runway. The probe trial was always nonrewarded and moved from Position 1 through Positions 2 and 3 to Position 4 within each successive block of 4 days for the first 24 days of training. The probe trial moved from Position 4 through Positions 3 and 2 to Position 1 within successive blocks of 4 days for the last 8 days of training. Table 1 presents the reinforcement schedules used on Days 1-12. The schedules were repeated in the same order for Days 13-24. Schedule A was used in reverse order (i.e., beginning with the probe trial in Position 4) on Days 25-28 and Schedule B was used in reverse order on Days 29-32.

\section{Results and Discussion}

All times were converted to speeds in centimeters per second. As in Experiment 1, only total speeds are reported here. Figure 2 shows the speed of running on the probe trials collapsed across the last 16 days of training as a function of the serial position of the probe trial. As can be seen, running speeds increased across trial positions along with the increase in reinforcement percentage in Group I and decreased across trial positions along with the decrease in reinforcement percentage in Group D. With the exception of slow running in Group I on Trial 1 of all days, always an $\mathrm{N}$ trial in that group, the observation of patterning was confined to the probe trials.

An ANOVA with groups (two) and brightness (two) as between-subjects variables and trial position (four) and blocks of four trials (four) as within-subjects variables was applied to speeds over the last 16 probe trials. The ANOVA yielded a highly reliable Groups by Trial Position interaction $[F(3,168)=24.13, p<.0001]$. Simple effects of trial position at each group showed that speeds increased across successive probe trials in Group I $[F(3,168)=16.16, p<.001]$ and decreased across successive trial positions in Group D $[F(3,168)=$

Table 1

Reinforcement Schedules in Blocks of 4 Days Used in Experiment 2 and Position of Probe Trial

\begin{tabular}{|c|c|c|c|c|c|}
\hline & \multirow[b]{2}{*}{ Schedule } & \multicolumn{4}{|c|}{ Position of Probe Trial } \\
\hline & & 1 & 2 & 3 & 4 \\
\hline Group I & $\begin{array}{l}\text { A } \\
\text { B } \\
\text { C }\end{array}$ & $\begin{array}{l}\text { N N R R } \\
\text { N N N R } \\
\text { N N N R }\end{array}$ & $\begin{array}{l}\text { N N R R } \\
\text { N N R R } \\
\text { N N R R }\end{array}$ & $\begin{array}{l}\text { N R N R } \\
\text { N N N R } \\
\text { N R N R }\end{array}$ & $\begin{array}{l}\text { N N R N } \\
\text { N R N N } \\
\text { N N R N }\end{array}$ \\
\hline Group D & $\begin{array}{l}\text { A } \\
\text { B } \\
\text { C }\end{array}$ & $\begin{array}{l}\text { N R N N } \\
\text { N N R N } \\
\text { NR N N }\end{array}$ & $\begin{array}{l}\text { R N R N } \\
\text { R N N N } \\
\text { R N N N }\end{array}$ & $\begin{array}{l}\text { R R N } \\
R \text { R N } \\
R \text { N N }\end{array}$ & $\begin{array}{l}R \text { R N } \\
R \mathbf{N} N \\
R N R N\end{array}$ \\
\hline
\end{tabular}




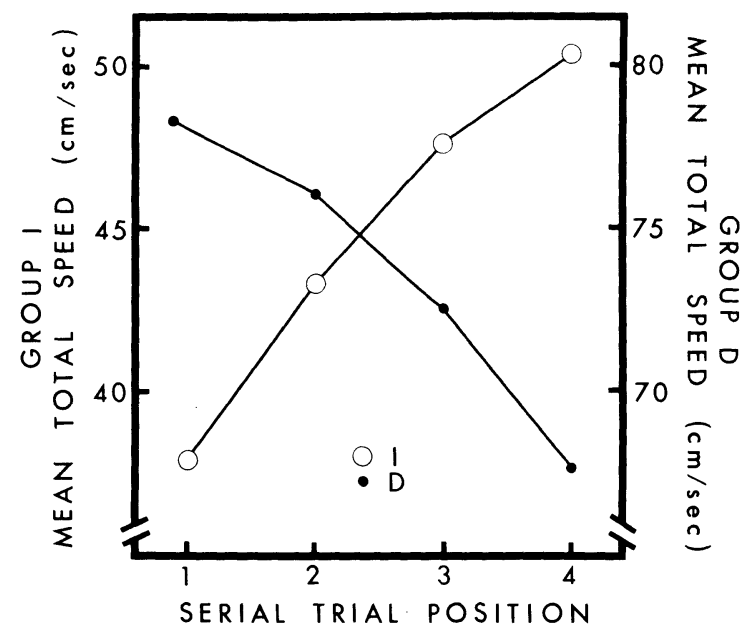

Figure 2. Mean speed for both groups in Experiment 2 on probe trials collapsed across the last 16 days of training as a function of the serial position of the probe trial.

9.47, $\mathrm{p}<.001]$. Thus; as in Experiment 1, speed of running on probe trials in Experiment 2 was a function of serial trial position within a day's trials and was directly related to the percentage of reinforcement associated with a given trial position.

\section{GENERAL DISCUSSION}

Capaldi and Verry (1981) have recently reported that the rat's ability to recall the number of successive $\mathrm{N}$ trials contained in a schedule is sufficiently accurate to suggest an ability to keep track of trials by counting. This ability appears not to be limited to keeping track of goal events. The rat can also discriminate the first trial of the day from subsequent trials (Capaldi \& Morris, 1974), and Davis (Note 1) reported that rats can keep track of at least three trials by counting.

The patterning behavior obtained in the present experiments could not be accomplished on the basis of differential response tendencies acquired to one or more preceding goal events, since neither $\mathrm{R}$ nor $\mathrm{N}$ on one trial reliably predicted $\mathrm{R}$ or $\mathrm{N}$ on the next trial. The patterning behavior obtained here could be a consequence, though, of differential values of $\mathrm{H}$ associated with each serial trial position if the rat can discriminate not just between Trial 1 and subsequent trials, but among several trials. It could do this if each trial were accompanied by some distinctive cue or if the rat could keep track of serial trial position by counting. The use of a probe trial, as in the present experiments, may allow differences in $\mathrm{H}$ associated with different trial positions, which might otherwise escape detection, to be measured.

Hulse (1978) suggested that rats learn monotonically increasing or decreasing patterns of reward magnitude by encoding a cognitive rule defining the pattern structure. In the case of a monotonically decreasing pattern, for example, the rat may learn that every element in the pattern is smaller than the immediately preceding one. None of the reinforcement schedules used in the present experiments, however, can be described by a rule stating a relationship between successive elements in the pattern. Nor is it clear that rats could encode such a complex and abstract a rule as "the probability of reinforcement increases (or decreases) across trials." While it would be difficult to account for the patterning behavior obtained here on the basis of rule encoding, the present results suggest that patterning behavior under monotonically increasing or decreasing schedules of reward magnitude of the kind employed by Hulse could be due in part to differences in $\mathrm{H}$ associated with each serial trial position.

\section{REFERENCE NOTE}

1. Davis, H. Can rats count to three? Paper presented to the annual meeting of the Psychonomic Society, Philadelphia, November 1981 .

\section{REFERENCES}

Bloom, J. M., \& CAPAldi, E. J. The behavior of rats in relation to complex patterns of partial reinforcement. Journal of Comparative and Physiological Psychology, 1961, 54, 261-265.

Bloom, J. M., Williams, D. T., \& Metze, L. P. Effects of varied and partial reward on discrete-trial patterning of rats. Animal Learning \& Behavior, 1973, 1, 167-170.

CAPAldi, E. J. Latent discrimination learning under a regular schedule of partial reinforcement. Animal Learning \& Behavior, 1979, 7, 63-68.

Capaldi, E. J., Blitzer, R. D., \& Molina, P. Serial anticipation pattern learning in two-element and three-element series. Bulletin of the Psychonomic Society, 1979, 14, 22-24.

Capaldi, E. J., \& Molina, P. Element discriminability as a determinant of serial-pattern learning. Animal Learning \& Behavior, 1979, 7, 318-322.

Capaldi, E. J., \& Morris, M. D. Reward schedule effects in extinction: Intertrial interval, memory and memory retrieval. Learning and Motivation, 1974, 5, 473-483.

Capaldi, E. J., \& Verry, D. R. Serial order anticipation learning in rats: Memory for multiple hedonic events and their order. Animal Learning \& Behavior, 1981, 9, 441-453.

HaggBloom, S. J. The differential reinforcement of rewardproduced and response-produced stimuli. Learning and Motivation, 1979, 10, 364-381.

HagGbloom, S. J. Resistance to discrimination and subsequent resistance to extinction as a function of the sequence of partial $\mathrm{S}+$ reward in differential conditioning. Animal Learning \& Behavior, 1980, 8, 441-446.

HaggBloom, S. J. Blocking in successive differential conditioning: Prior acquisition of control by internal cues blocks the acquisition of control by brightness. Learning and Motivation, 1981, 12, 485-508.

Haggbloom, S. J., \& Tillman, D. J. Sequential Effects on discrimination reversal. Learning and Motivation, 1980, 11, 318-338.

HuLSE, S. H. Cognitive structure and serial pattern learning by rats. In S. H. Hulse, H. Fowler, \& W. K. Honig (Eds.), Cognitive processes in animal behavior. Hillsdale, N.J: Erlbaum, 1978.

McHose, J. H., \& Blackwell, D. R. Performance in differential instrumental conditioning as a function of the pattern of partial S+ reward. Animal Learning \& Behavior, 1975, 3, 63-66.

(Received for publication October 21, 1981.) 